\title{
Antifertility effects of tetradecyl sodium sulphate in rabbits
}

\author{
R. E. Zimmerman, R. S. Nevin, D. J. Allen, C. D. Jones, M. E. Goettel \\ and P. J. Burck
}

Biochemical, Organic, and Physical Chemistry Research Departments, Lilly Research Laboratories, Indianapolis, Indiana 46285, U.S.A.

\begin{abstract}
Summary. Acrosin and acrosomal hyaluronidase were inhibited by tetradecyl sodium sulphate (TDSS) in vitro at concentrations of $<10^{-4} \mathrm{M}$. TDSS prevented the removal in vitro of the cumulus oophorus by testicular hyaluronidase and the zona pellucida by acrosin. TDSS had a contraceptive effect in rabbits when administered intravaginally before coitus or released at levels of $1-3 \mu \mathrm{g} /$ day from intrauterine silicone rubber devices.
\end{abstract}

\section{Introduction}

Hyaluronidase (EC 3.2.1.35) has been shown to be associated with the sperm acrosome (Austin, 1960; Masaki \& Hartree, 1962) and to disperse the cumulus oophorus during fertilization (McClean \& Rowlands, 1942; Yang \& Srivastava, 1975). Inhibitors of hyaluronidase prevented the removal of the cumulus oophorus in vitro (Metz, 1972) and inhibited fertilization (Pincus, Pirie \& Chang, 1948; Chang \& Pincus, 1953; Parkes, Rogers \& Spensley, 1954; Reddy, Joyce \& Zaneveld, 1980).

Acrosin (EC 3.4.21.10) has been implicated as the enzyme responsible for penetration of the zona pellucida by spermatozoa (Stambaugh \& Buckley, 1969). Meizel \& Lui (1976) first suggested that acrosin also plays a role in the acrosome reaction of mammalian spermatozoa. Inhibitors of acrosin, naturally occurring and synthetic, will prevent fertilization (Stambaugh, Brackett \& Mastroianni, 1969; Zaneveld, Robertson \& Williams, 1970; Zaneveld, Robertson, Kessler \& Williams, 1971; Meizel \& Lui, 1976).

Since inhibitors of acrosin or hyaluronidase will inhibit fertilization, a compound which inhibits both acrosin and hyaluronidase activity should have high potential as a contraceptive agent. In the present paper the activity of tetradecyl sodium sulphate was investigated.

\section{Materials and Methods}

Materials. Hyaluronidase type III from ovine testes, chondroitin sulphate grade III, and $N-\alpha-$ benzoyl-DL-arginine $p$-nitroanilide (BAPNA) were obtained from Sigma Chemical Company (St Louis, Missouri, U.S.A.). D-Phenylalanyl-piperidyl-valyl-arginyl-p-nitroanilide (S2238) was purchased from Orthodiagnostics, Inc. (Raritan, New Jersey, U.S.A.).

Synthesis of tetradecyl sodium sulphate. TDSS is commercially available from several suppliers, but all of the purchased samples evaluated were significantly contaminated by $\mathrm{C}_{10}, \mathrm{C}_{12}$ and $\mathrm{C}_{16}$ alkyl sulphates. Tetradecyl sodium sulphate was therefore prepared by sulphation of $>98 \%$ pure 1 - 
tetradecanol purchased from Continental Oil Co. (Houston, Texas, U.S.A.) using chlorosulphonic acid according to the procedure of Dreger, Keim, Miles, Shedlovsky \& Ross (1944). The TDSS obtained was $99.6 \%$ pure by gas chromatography.

Assay for hyaluronidase inhibition. Radial diffusion assays were done on agar plates containing $0.1 \%$ chondroitin sulphate and $1.0 \%$ agarose in $1.0 \mathrm{M}$-sodium acetate buffer $\mathrm{pH} 5.0$. Results were reported as percentage of standard. The hydrolysis of chondroitin sulphate can also be measured colorimetrically according to the procedure of Linker (1974). Kinetic assays were done using this colorimetric procedure.

Assay for acrosin inhibition. Boar sperm acrosin was isolated from washed, ejaculated boar spermatozoa by the extraction procedure of Srivastava (1973). The extract was acidified and further purified by gel filtration on Sephadex G-50F and G-100 columns equilibrated at $5^{\circ} \mathrm{C}$ with $0.01 \mathrm{~N}-\mathrm{HCl}$. Final purification was achieved by affinity chromatography of the acrosin on a column of $p$-aminobenzamidine bound to $\mathrm{CH}$-Sepharose using a modification of the method described by Schleuning, Schiessler \& Fritz (1973).

Boar sperm acrosin with a specific activity of $14.7 \mathrm{i} . \mathrm{u} . / \mathrm{mg}$ was used to measure acrosin inhibition. Then $200 \mu \mathrm{l}$ of a solution of TDSS were added to $200 \mu \mathrm{l}$ acrosin solution and incubated at $25^{\circ} \mathrm{C}$ for $5 \mathrm{~min}$. This solution $(200 \mu \mathrm{l})$ was pipetted into $2.8 \mathrm{ml}$ of a $0.33 \mathrm{mg} / \mathrm{ml}$ solution of BAPNA or a $3.0 \times 10^{-4} \mathrm{M}$ solution of $\mathrm{S} 2238$ in $0.05 \mathrm{M}$-triethanolamine, $\mathrm{pH} \mathrm{7.8}$. The increase in absorbance at $405 \mathrm{~nm}$ during the first 2 min of reaction at $25^{\circ} \mathrm{C}$ was recorded using a Gilford Model 240 spectrophotometer. (One inhibition unit caused the reduction of BAPNA hydrolysis by 0.001 absorbance $_{383}$ unit per min per $\mathrm{ml}$ of inhibitor using a $1 \mathrm{~cm}$ light path.)

In-vivo antifertility assays. A solution of $10 \mathrm{mg} / \mathrm{ml}$ or $1 \mathrm{mg} / \mathrm{ml}$ of TDSS in calcium free Ringer's solution $\left(0.9 \% \mathrm{NaCl}, 0.04 \% \mathrm{KCl}, 0.02 \% \mathrm{NaHCO}_{3}, \mathrm{pH} 7.4\right)$ was suspended in an equal volume of KY-Jelly (Johnson and Johnson, New Brunswick, New Jersey, U.S.A.), and $1 \mathrm{ml}$ of this suspension was placed into the vagina of Dutch belted female rabbits. They were mated to bucks of proven fertility within 15 min of the insertion of the TDSS. Each female received 100 i.u. hCG intravenously to ensure ovulation. The rabbits were caged in a constant temperature room on a 14-h light/10-h dark cycle. Animals were killed 14 days after mating, and the number of live embryos was counted.

Short-term intrauterine antifertility experiments. Tetradecyl sodium sulphate was incorporated into silicone rubber implants at a level of $10 \%(w / w)$ by thoroughly mixing the compound with Dow Corning MDX4-4210 elastomer (10 parts) and Dow Corning MDX4-4210 curing agent (1 part) (Dow Corning, Midland, Michigan, U.S.A.). This mixture was deaerated in vacuo for 30 min and allowed to equilibrate at atmospheric pressure for $15 \mathrm{~min}$. Rods were formed by drawing the mixture up into nominal $1.5 \mathrm{~mm}$ diameter glass tubing by vacuum. Vulcanization was carried out at $120^{\circ} \mathrm{C}$ for $10 \mathrm{~min}$. After standing for $24 \mathrm{~h}$ at ambient temperature, the rods were removed. Rods prepared in this way were cut into implants of $10 \mathrm{~mm}$ length which weighed about $40 \mathrm{mg}$ and contained about $4 \mathrm{mg}$ TDSS. The implants were sterilized with ethylene oxide, and aseptic measures were used during storage and handling.

The sterilized silicone rods were implanted into Dutch belted virgin female rabbits, weighing approximately $3 \mathrm{~kg}$, by making an incision through the uterine wall and suturing either a blank silicone implant or an implant containing TDSS at a random point along the right uterine horn. The left uterine horn was left intact to serve as a control. The females were allowed to recover from the surgery for 14 days. Sterile penicillin G (Duracillin: Eli Lilly, Indianapolis, Indiana U.S.A.), 300000 units, was administered i.m. daily for the first 4 days of the recovery period. After recovery. the does were mated to bucks of proven fertility and treated as described above.

In-vivo release of TDSS from silicone rubber rods. TDSS-loaded silicone rubber rods were implanted into uteri of female Dutch belted rabbits as described above. At various times the animals were killed and the implants removed. The silicone rubber rods were cut up into small pieces and extracted for $24 \mathrm{~h}$ with $50 \mathrm{ml}$ refluxing methanol. The amount of TDSS extracted was measured using methylene blue according to the procedure of Hayashi (1975). This value was 
subtracted from the average amount of TDSS originally present in a $10 \%$ TDSS loaded rod to obtain the amount of TDSS released.

Autoradiography of sperm binding. Freshly ejaculated rabbit semen was collected using an artificial vagina. The spermatozoa were separated by centrifugation and washed three times in $\mathrm{Ca}^{2+}$-free Ringer's solution. The washed spermatozoa were incubated with a $0.02 \mathrm{mg} / \mathrm{ml}$ solution of tritium-labelled TDSS $(781.5 \mu \mathrm{Ci} / \mathrm{mmol}$ ), obtained from New England Nuclear (Boston, Massachusetts, U.S.A.), in $\mathrm{Ca}^{2+}$-free Ringer's solution at $37^{\circ} \mathrm{C}$. The spermatozoa were incubated with $\left[{ }^{3} \mathrm{H}\right]$ TDSS for $10 \mathrm{~min}$ and then washed three times in $\mathrm{Ca}^{2+}$-free Ringer's solution to wash away unbound $\left[{ }^{3} \mathrm{H}\right]$ TDSS. The washed spermatozoa were then resuspended in $\mathrm{Ca}^{2+}$-free Ringer's solution and layered onto an agarose plate prepared with $1.5 \%$ agarose (Chemical Dynamics Corporation, Plainfield, New Jersey U.S.A.) in $\mathrm{Ca}^{2+}$-free Ringer's solution. After standing for 30 min, the plates were overlayed with LKB Ultrafilm (LKB Instruments, Inc., Rockville, Maryland, U.S.A.) and incubated in a dark room at ambient temperature for 2 weeks. The film was then developed using standard procedures and examined.

Long-term intrauterine antifertility experiments. These experiments were performed using the same surgical techniques as previously described. A silicone rubber rod containing TDSS was sutured at a random point along each uterine horn of 6 female Dutch belted rabbits. After these animals recovered from surgery they were mated to bucks of proven fertility at weekly intervals for 35 weeks. Immediately after each mating the females were injected i.v. with 100 i.u. hCG to ensure good ovulation rates. The females were examined for pregnancy by palpation during the entire course of the study. At the end of the experiment the uterus of each of the animals was examined for pathology.

\section{Results}

In-vitro inhibition of acrosin and hyaluronidase

A Lineweaver-Burk plot of the inhibition of acrosin activity by concentrations of TDSS well below the critical micelle concentration of $10^{-4} \mathrm{M}$ (Winsor, 1948) is shown in Text-fig. 1. BAPNA $\left(K_{\mathrm{m}}=5.0 \times 10^{-4} \mathrm{M}\right)$ was used for this study. Similar results were observed when the more sensitive substrate $\mathrm{S} 2238\left(K_{\mathrm{m}}=4.9 \times 10^{-5} \mathrm{M}\right)$ was used. Using S2238 as the substrate a $K_{\mathrm{i}}$ of $7.82 \times 10^{-7} \mathrm{M}$

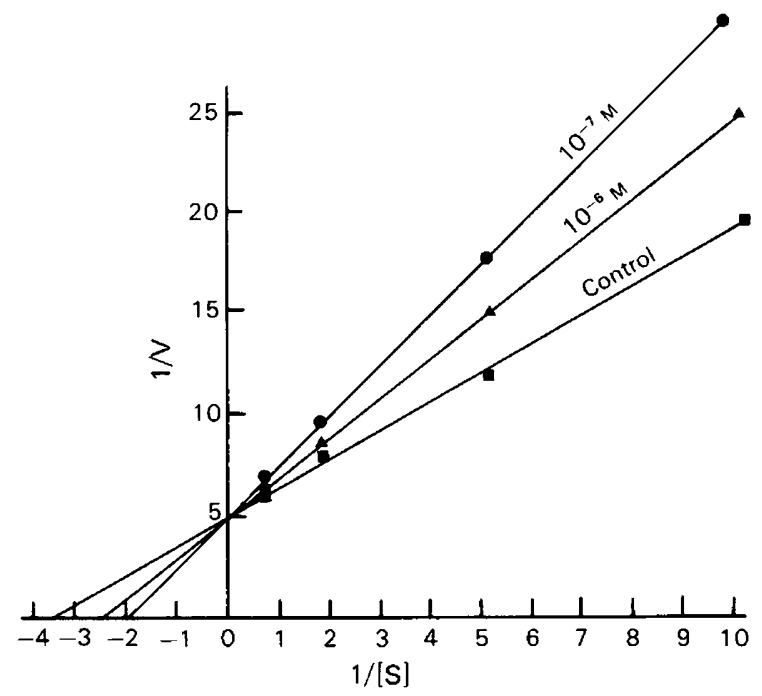

Text-fig. 1. A Lineweaver-Burk plot of the inhibition of acrosin by solutions of TDSS (V = units of acrosin activity). 
was determined for TDSS and acrosin. Inhibition of hyaluronidase was also observed at concentrations of TDSS less than the critical micelle concentration (Text-fig. 2), but because of substrate inhibition by chondroitin sulphate and the lack of sensitivity of the colorimetric assay, Lineweaver-Burk plots could not be constructed.

Effect of TDSS on sperm motility and egg penetration in vivo

Tetradecyl sodium sulphate inhibited the removal of the cumulus oophorus from ova by testicular hyaluronidase in vitro. It also inhibited the removal of the zona pellucida by acrosin in vitro but did not affect motility when spermatozoa were exposed to $3 \times 10^{-4} \mathrm{M}$-TDSS for $1 \mathrm{~h}$ at $37^{\circ} \mathrm{C}$.

\section{Intravaginal antifertility effects}

When Dutch-belted rabbits were treated intravaginally with $5 \mathrm{mg}$ TDSS before coitus, a total contraceptive effect was observed. When $0.5 \mathrm{mg}$ was administered in the same manner, pregnancy rates were not affected. The control group, receiving $\mathrm{KY}$-Jelly alone, showed a reduction in pregnancy rates compared to untreated animals, but the difference was not statistically significant (Table 1).

\section{Binding of TDSS to sperm membranes}

Tetradecyl sodium sulphate bound washed rabbit spermatozoa when suspensions of spermatozoa were incubated with TDSS at $37^{\circ} \mathrm{C}$. The binding was direcily proportional to the

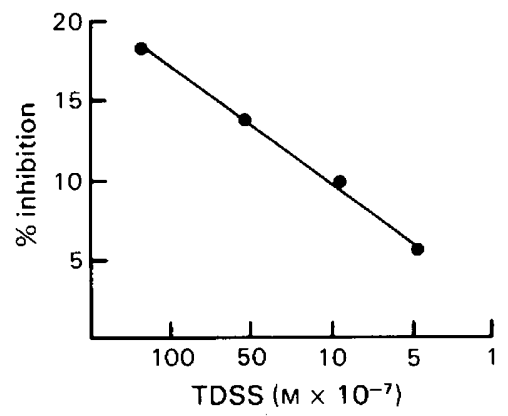

Text-fig. 2. Inhibition of hyluronidase by TDSS in a radial diffusion assay on agarose plates. Percentage inhibition was determined by subtracting the area of hydrolysis of assays containing various dilutions of TDSS from that of the standard. The difference was then calculated as a percentage of the standard.

Table 1. The contraceptive effect of tetradecyl sodium sulphate (TDSS) administered intravaginally in rabbits

\begin{tabular}{lcccc}
\hline Treatment & Animals & $\begin{array}{c}\text { No. of } \\
\text { embryos }\end{array}$ & $\begin{array}{c}\text { No. of } \\
\text { corpora } \\
\text { lutea }\end{array}$ & $\begin{array}{c}\% \\
\text { Pregnancy } \\
\text { (embryos/CL) }\end{array}$ \\
\hline $\begin{array}{l}\text { Control } \\
\text { (untreated) }\end{array}$ & 6 & 29 & 35 & 83 \\
Vehicle & 5 & 13 & 29 & 45 \\
5 mg TDSS & 5 & 0 & 32 & $0^{*}$ \\
0.5 mg TDSS & 5 & 8 & 36 & 22 \\
\hline
\end{tabular}

* Significantly different from the control value $(P<0.05)$ (Student's $t$ test). 
number of spermatozoa present (Text-fig. 3). Approximately $10^{5}$ spermatozoa bound $1 \mu \mathrm{g}$ TDSS in vitro. The binding of TDSS to sperm membranes was confirmed by autoradiographic experiments which showed that $\left[{ }^{3} \mathrm{H}\right]$ TDSS bound to the entire sperm plasma membrane surface and not just specifically to the acrosomal membranes.

\section{Intrauterine antifertility studies}

The data in Table 2 indicate that $1-3 \mu \mathrm{g}$ TDSS released/day from a silicone rubber implant in the uterus had total contraceptive effect in the rabbit. The silicone rubber implant itself had no effect on the numbers of embryos compared to those in untreated horns. The release rate of TDSS from silicone rubber implants in vivo was variable, but both the short-term release data and that at 60,120 and 180 days remained in the range of $1-3 \mu \mathrm{g} /$ day (Table 3 ).

In the long-term antifertility experiments none of the 6 animals with a TDSS silicone rubber implant in each uterine horn became pregnant. Untreated controls or controls with blank silicone rubber implants were not used for this study because they would have become pregnant after the first mating. When the female rabbits were killed and the genital tracts examined after 35 weeks, no evidence of infection or occlusion of the uterine horns or oviducts was observed. The ovaries contained many corpora lutea.

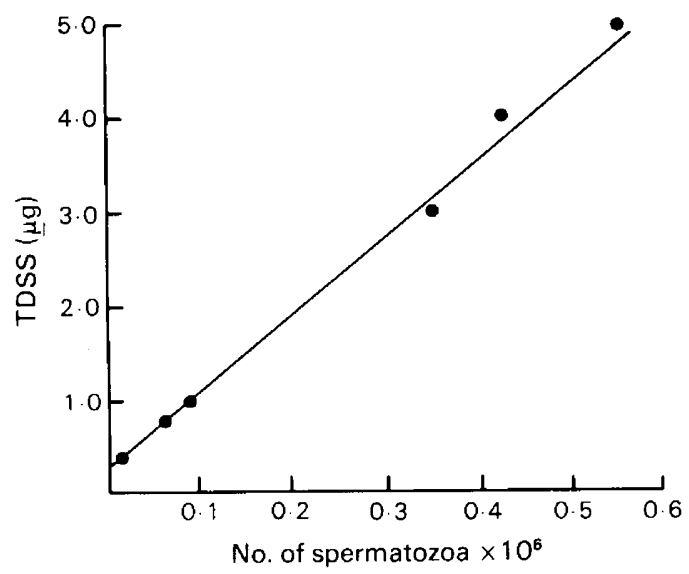

Text-fig. 3. Binding of TDSS to rabbit spermatozoa using methylene blue which forms a complex with TDSS. Micrograms of TDSS were calculated from a standard curve of known amounts of TDSS against absorbance of the methylene blue-TDSS complex at $640 \mathrm{~nm}$.

Table 2. Inhibition of pregnancy in rabbits by TDSS, administered by release from silicone rubber rods

\begin{tabular}{llcccc}
\hline Treatment & Horn & $\begin{array}{c}\text { No. of } \\
\text { uterine } \\
\text { horns }\end{array}$ & $\begin{array}{c}\text { No. of } \\
\text { embryos }\end{array}$ & $\begin{array}{c}\text { No. of } \\
\text { corpora } \\
\text { lutea }\end{array}$ & $\begin{array}{c}\text { Mean } \pm \text { s.d. } \\
\text { no. of } \\
\text { embryos }\end{array}$ \\
\hline None & & 10 & 17 & 24 & $1 \cdot 4 \pm 0.5$ \\
Blank rod & Treated & 13 & 14 & 24 & $1 \cdot 1 \pm 0 \cdot 5$ \\
TDSS-impregnated rod & Contralateral & 13 & 19 & 24 & $1.5 \pm 1 \cdot 0$ \\
& Treated & 8 & 0 & 14 & $1.5 \pm 0.8$ \\
\hline
\end{tabular}

* Significantly different from controls $(P<0 \cdot 01)$ (Student's $t$ test). 
Table 3. In-vivo release of TDSS from silicone rubber rods

\begin{tabular}{ccc}
\hline Days in utero & $\begin{array}{c}\text { TDSS released } \\
(\mu \mathrm{g})^{*}\end{array}$ & $\mu \mathrm{g}$ TDSS/day \\
\hline 3 & $7 \cdot 50$ & $2 \cdot 50$ \\
4 & 4.80 & $1 \cdot 20$ \\
5 & $5 \cdot 00$ & $1 \cdot 00$ \\
6 & $6 \cdot 60$ & $1 \cdot 10$ \\
7 & $7 \cdot 70$ & $1 \cdot 10$ \\
13 & $29 \cdot 25$ & $2 \cdot 25$ \\
60 & 135.00 & $2 \cdot 25$ \\
120 & 216.00 & 1.80 \\
180 & 648.00 & 3.60 \\
\hline
\end{tabular}
rods.

* Values are means for 3 rabbits each containing 2

\section{Discussion}

Tetradecyl sodium sulphate inhibited the activity of acrosin and hyaluronidase in vitro at concentrations $<10^{-4} \mathrm{M}$, and at such concentrations TDSS was a competitive inhibitor of acrosin, apparently binding to an active site on the enzyme. Our experiments with intravaginal application of TDSS indicate that complete inhibition of pregnancy can be obtained in rabbits. However, since acrosin and hyaluronidase exert their effects in the oviducts, TDSS must get to this site from the vagina to be active. It must, therefore, either pass through the sperm acrosomal membranes and inactivate acrosin and hyaluronidase or bind to the spermatozoa in the vagina and be transported to the site of the enzyme activities. We have shown that $10^{5}$ spermatozoa will bind $1 \mu \mathrm{g}$ TDSS.

If TDSS inhibits pregnancy by binding to spermatozoa and being transported to the site of fertilization, then approximately $1 \mu \mathrm{g}$ TDSS in the uterus should inhibit pregnancy since approximately $10^{5}$ spermatozoa have been shown to be present in the rabbit uterus after coitus (Braden, 1953; Morton, 1970; Overstreet, Cooper \& Katz, 1978). Sustained and controlled release of microgram amounts of TDSS in the uterus $(1-3 \mu \mathrm{g} /$ day) was accomplished using silicone rubber intrauterine implants.

The results of these experiments show clearly that TDSS, a potent acrosin and hyaluronidase inhibitor, has contraceptive activity. The compound can be delivered from an intrauterine implant which releases microgram amounts of TDSS into the uterine lumen for extended periods of time. The use of TDSS in an intrauterine system would avoid the complications associated with the use of steroids, and its contraceptive action would not depend on endometrial contact or irritation.

\section{References}

Austin, C.R. (1960) Capacitation and the release of hyaluronidase from spermatozoa. J. Reprod. Fert. 1, 310-311.

Braden, A.W.H. (1953) Distribution of sperm in the genital tract of the female rabbit after coitus. Aust. $J$. biol. Sci. 6, 693-705.

Chang, M.C. \& Pincus, G. (1953) Does phosphorylated hesperidin affect fertility? Science, N.Y. 117, 224 236.

Dreger, E.E., Keim, G.I., Miles, G.D., Shedlovsky, L. \& Ross, J. (1944) Sodium alcohol sulfates: properties involving surface activity. Ind. and Eng. Chem. 36, 610-617.
Hayashi, K. (1975) A rapid determination of sodium dodecyl sulfate with methylene blue. Analyt. Biochem. 67, 503-506.

Linker, A. (1974) Hyaluronidase. In Methods of Enzyme Analysis, pp. 944-947. Ed. H. U. Bergmeyer. Academic Press, New York.

Masaki, J. \& Hartree, E.F. (1962) Distribution of metabolic activity, phospholipid and hyaluronidase between the heads and tails of bull spermatozoa. Biochem. J. 84, 347-353.

McClean, D. \& Rowlands, I.W. (1942) Role of hyaluronidase in fertilization. Nature, Lond. 150, 627-628.

Meizel, S. \& Lui, C.W. (1976) Evidence for the role of a 
trypsin-like enzyme in the hamster sperm acrosome reaction. J. exp. Zool. 195, 137-144.

Metz, C.B. (1972) Effects of antibodies on gametes and fertilization. Biol. Reprod. 6, 358-383.

Morton, D.B. (1970) On the transport of spermatozoa in the female tract. Ph.D. thesis, University of Liverpool.

Overstreet, G.W., Cooper, G.W. \& Katz, D.F. (1978) Sperm transport in the reproductive tract of the female rabbit. II. The sustained phase of transport. Biol. Reprod. 19, 115-132.

Parkes, A.S., Rogers, H.J. \& Spensley, P.C. (1954) Biological and biochemical aspects of the prevention of fertilization by enzyme inhibitors. Stud. Fertil. 6, 6580.

Pincus, G., Pirie, N.W. \& Chang, M.C. (1948) The effects of hyaluronidase inhibitors on fertilization in the rabbit. Archs Biochem. Biophys. 19, 388-396.

Reddy, J.M., Joyce, C. \& Zaneveld, L.J.D. (1980) Role of hyaluronidase in fertilization: the antifertility activity of myocrisin, a nontoxic hyaluronidase inhibitor. J. Androl. 1, 28-32.

Schleuning, W.D., Schiessler, H. \& Fritz, H. (1973) Highly purified acrosomal proteinase (boar acrosin): isolation by affinity chromatography using benzamidine-cellulose and stabilization. Hoppe-Seyler's Z. Physiol. Chem. 354, 550-554.
Srivastava, P.N. (1973) Removal of acrosomes of ram and rabbit spermatozoa. J. Reprod. Fert. 33, 323-326.

Stambaugh, R. \& Buckley, J. (1969) Identification and subcellular localization of the enzyme effecting penetration of the zona pellucida by rabbit spermatozoa. J. Reprod. Fert. 19, 423-432.

Stambaugh, R., Brackett, B.G. \& Mastroianni, L. (1969) Inhibition of in vitro fertilization of rabbit ova by trypsin inhibitors. Biol. Reprod. 1, 223-227.

Winsor, P.A. (1948) Effect of constitution on amphiliphilic properties. Trans. Faraday Soc. 44, 463-471.

Yang, C.H. \& Srivastava, P.N. (1975) Purification of bull sperm hyaluronidase by concanavalin A affinity chromatography. Biochim. Biophys. Acta 391, 382387.

Zaneveld, L.J.D., Robertson, R.T. \& Williams, W.L. (1970) Synthetic enzyme inhibitors as antifertility agents. Fedn Eur. Biochem. Soc. Lett. 11, 345-347.

Zaneveld, L.J.D., Robertson, R.T., Kessler, M. \& Williams, W.L. (1971) Inhibition of fertilization in vivo by pancreatic and seminal plasma trypsin inhibitors. J. Reprod. Fert. 25, 387-392.

Received 10 August 1982 